Authors'reply: Sue Kemsley has raised some important issues regarding ECT. The use of ECT without consent has not declined in absolute numbers since 1985 but, as discussed in our editorial (Eranti \& McLoughlin, 2003), the total number of patients receiving ECT has substantially fallen during this period. Little research has been directed at understanding this change in the pattern of ECT use. One possibility is that there exists a core group of patients with severe depressive illness and possible psychosis that requires treatment with ECT, while the decline in use predominantly occurs in people with less severe illness. So why has the use of ECT declined in this latter group?

As we have already suggested, we believe that this is due to historical changes in general psychiatry, especially psychopharmacology. One has to bear in mind that, following its introduction in 1938, ECT was one of the first truly effective treatments for severe debilitating psychiatric disorders and thus its use rapidly became widespread (Fink, 2001). We are currently investigating trends in ECT practice over the past 50 years in the Maudsley and Bethlem Royal Hospitals in south London. Its use peaked in 1956 when $34 \%$ of admissions were treated with ECT. This rate fell steadily thereafter to $30 \%$ in $1959,21 \%$ in 1968 and $5 \%$ in 1987 . It is interesting to note here that imipramine was introduced in 1958, coinciding with the beginning of this decline in use of ECT. Similarly, ECT use further declined after the introduction of fluoxetine, the first of the selective serotonin reuptake inhibitors, in 1988 , such that by $19912 \%$ of admissions received ECT. Currently, less than $1 \%$ of admissions are treated with ECT and nearly $90 \%$ of these have a diagnosis of major depressive disorder, which is wellestablished as being the main indication for contemporary ECT (Carney et al, 2003).

Carney, S., Cowen, P., Geddes, J., et al (2003) Efficacy and safety of electroconvulsive therapy in depressive disorders: a systematic review and meta-analysis. Lancet, 361, 799-808.

Eranti, S. V. \& McLoughlin, D. M. (2003)

Electroconvulsive therapy - state of the art. British Journal of Psychiatry, 182, 8-9.

Fink, M. (200I) Convulsive therapy: a review of the first 55 years. Journal of Affective Disorders, 63, I-15.

S. V. Eranti, D. M. McLoughlin Institute of Psychiatry, Section of Old Age Psychiatry, Box PO70, De Crespigny Park, Denmark Hill, London SE5 8AF, UK

\section{Inappropriate use of psychostimulants}

Rey \& Sawyer (2003) ask 'Are psychostimulant drugs being used appropriately to treat child and adolescent disorders?' the answer is no. Like most articles on psychostimulants, they avoid discussion of the fundamental question that needs tackling for their conclusions to have any meaning - is attention-deficit hyperactivity disorder (ADHD) a valid medical disorder? The answer is no (see Timimi, 2002). This disorder is best understood as a cultural creation. Rey \& Sawyer illustrate how deeply practice in this area is influenced by cultural dynamics. They show how there are large variations in the way diagnostic criteria are used both between countries (not surprisingly, they only mention Western ones) and within them. They show that there are also large variations in the way psychostimulants are used.

Children are already the losers here. There are reports of some primary schools where nearly $40 \%$ of the students were taking psychostimulants (Runnheim, 1996). Rates of diagnosis of ADHD and subsequent medication use continue to rise alarmingly in most Western countries. This is a massive, dangerous and scandalous experiment in which millions of children are being exposed to highly toxic, addictive and brain-disabling drugs whose mediumand long-term efficacy and safety have not been established (Breggin, 2002). The only winner is the profit margin of the pharmaceutical industry.

I realise this is emotive language, but then the business of what values we hold when it comes to children is too important to allow us to hide behind dry, detached, academic pretence. We live in a culture that has a deep intolerance for children. This is at the heart of why we are labelling physically healthy children with fictional medical disorders. Doctors become a symptom of this intolerance, not part of the solution.

This is all so unnecessary. For years I have been working with these children and their families using diverse perspectives based on a more humanitarian value system (Timimi, 2002). Not only are my clients grateful for this, they often recommend others to come and see me.

Breggin, P. (2002) The Ritalin Fact Book. Cambridge, MA: Perseus.

Rey, J. M. \& Sawyer, M. G. (2003) Are psychostimulant drugs being used appropriately to treat child and adolescent disorders? British Journal of Psychiatry, $\mathbf{1 8 2}$, 284-286.

Runnheim, V. A. (1996) Medicating students with emotional and behavioural disorders and ADHD: a state survey. Behavioural Disorders, 2I, 306-3I4.

Timimi, S. (2002) Pathological Child Psychiatry and the Medicalization of Childhood. Hove: Brunner-Routledge.

S. Timimi Child and Adolescent Mental Health Services, Ash Villa, Willoughby Road, Sleaford, Lincolnshire NG34 8QA, UK

\section{Stigma as a cause of suicide}

We read with great interest the article by Eagles et al (2003) in which, among the various interventions discussed to prevent suicide, it was suggested that according to patients' opinions there should be a decrease in the stigma attached to psychiatric illness. We share that opinion and suggest that another goal of suicide prevention is the reduction of the stigma attached to suicide.

The term stigma refers to a mark that denotes a shameful quality in the individual so marked. Mental illness is widely considered to be such a quality, an assumption supported by a number of beliefs such as the association between mental illness and irrational and unpredictable violence as portrayed by the media and the notion that mental illness is not a 'true' illness like organic disease. And yet, people do fear mental illness and do not know how to avoid it by following the types of precautions and guidelines available for so many organic disorders.

Not only does the stigmatisation of mental illness prevent people from seeking treatment, which in turn exposes them to a greater risk of suicide, but also suicide can appear to be the best solution for a stigmatised individual. A number of environments can be traced where this process takes place. In the family, the family members' relationship to the patient may affect the extent to which the patient's stigma is transferred to the family members, as in the case of schizophrenia (Phelan et al, 1998). In such extreme cases, difficulties in dealing with a chronic disease, which often results in relapses, hospitalisations and social impairment, leads family members to stigmatise the patients. They behave in a way that may lead the patient to assume that suicide might be a solution for their situation. Family members may also unconsciously believe that suicide might be a solution. In the hospital, staff's 
attitudes towards patients who are at risk of suicide deserve consideration. Acceptance of a patient's suicide as a solution to problems, wishes that a patient would commit suicide as a solution to his or her problem, fear of the patient and difficulties in dealing with suicidal individuals are some of the most important sources of stigma in mental health environments. Also, following an attempt many individuals feel isolated or ignored by health professionals (McGaughey et al, 1995). In the military environment, stigma towards mental illness is very strong and military personnel tend to deny any form of mental disorder unless they are hoping to get another job. This exposes such a population to the risk of suicide.

Yet suicide is, itself, a source of stigma as anyone with suicidal ideation is considered weak, shameful, sinful and selfish, which prevents these individuals from seeking treatment early in the suicidal process. These judgements are often shared by active churchgoers (Sawyer \& Sobal, 1987), teachers and parents. Also, parents and widows of victims of suicide are stigmatised, which makes recovery from this type of loss particularly difficult (Smith et al, 1995). Destigmatisation should be addressed to mental illness as well as suicide. Increasing the stigma associated with having suicidal feelings will increase the suicide rate. Interventions among families, mental health professionals, military personnel and church activists aimed at decreasing the stigma associated with mental illness and suicide may contribute to the reduction of deaths by suicide.

Eagles, J. M., Carson, D. P., Begg, A., et al (2003) Suicide prevention: a study of patients' views. British Journal of Psychiatry, 182, 261-265.

McGaughey, J., Long, A. \& Harrison, S. (1995) Suicide and parasuicide: a selected review of the literature. Journal of Psychiatric and Mental Health Nursing, 2, 199-206.
Phelan, J. C., Bromet, E. J. \& Link, B. G. (1998) Psychiatric illness and family stigma. Schizophrenia Bulletin, 24, 115-126.

Sawyer, D. \& Sobal, J. (1987) Public attitudes toward suicide: demographic and ideological correlates. Public Opinion Quarterly, 5I, 92-10।.

Smith, B. I., Mitchell, A. M., Bruno, A. A. et al (1995) Exploring widows' experience after suicide of their spouse. Journal of Psychosocial Nursing and Mental Health Services, 33, 10-15.

\section{Pompili, I. Mancinelli, R. Tatarelli}

Dipartimento di Scienze Psichiatriche, Università

'La Sapienza', Via Panama 68, 00198 Roma, Italy

\section{Social capital and mental health v. objective measures of health in The Netherlands}

McKenzie et al (2002) reported that social capital in the neighbourhood may be beneficial for health and mental health in adults. We have reported associations between neighbourhood social capital and mental health service use in children (Van der Linden et al, 2003). We wished to investigate whether such effects on mental health were accompanied by similar effects on physical development, and investigated sensitive, $\mathrm{Cu}-$ mulative objective measures of child health, height and weight at different ages, in relation to the neighbourhood environment.

We recorded all height and weight data registered regularly in the Municipal Youth Health Care Centre from birth up to the baseline measurement of our cohort study of 1009 children aged approximately 11 years living in the 36 neighbourhoods of a Dutch city (response rate of both child and one parent of 54\%) (Drukker et al, 2003). This study on the effects of neighbourhood variables also included familylevel and child-level measures, such as family socioeconomic status. In addition, social capital dimensions of (a) informal social control and (b) social cohesion and trust were measured in a community survey and aggregated to neighbourhood level.
Data were part of a three-level structure with height and weight measurements at different ages nested within children, and children nested within neighbourhoods. Growth curves were estimated using a multi-level random-effects regression model (including age and age $^{2}$ ). The outcome measures were height, weight, and body mass index (weight/height ${ }^{2}$ ), and all variables except for age were considered fixed factors. When neighbourhood variables and individual level confounders were added to the models, results showed that none of the social capital measures was associated with any of the outcomes.

Therefore, we conclude that neighbourhood measures play a role in mental health, but that effects are more readily expressed in the psychological rather than the physical domain, in children living in The Netherlands.

Drukker, M., Kaplan, C. D., Feron, F. J. M., et a (2003) Children's health-related quality of life, neighbourhood socio-economic deprivation and social capital. A contextual analysis. Social Science and Medicine, 57, 825-84I.

McKenzie, K., Whitley, R. \& Weich, S. (2002) Socia capital and mental health. British Journal of Psychiatry I8I, 280-283.

Van der Linden, J., Drukker, M., Gunther, N., et al (2003) Children's mental health service use neighbourhood socio-economic deprivation and social capital. Social Psychiatry and Psychiatric Epidemiology, in press.

M. Drukker, N. Gunther Department of Psychiatry and Neuropsychology, Maastricht University, The Netherlands

F. J. M. Feron Youth Health Care Divison Municipal Health Centre, Maastricht, The Netherlands

J. van Os Department of Psychiatry and Neuropsychology, Maastricht University, POBox 616, 6200 MD Maastricht, The Netherlands, and Division of Psychological Medicine, Institute of Psychiatry, London, UK

\section{One hundred years ago}

\section{Epileptic colony, Ewell, Surrey}

ON Wednesday, July 1st, the first ratesupported epileptic colony in this country, founded by the London County Council for the epileptic insane of the metropolis, was opened by H.R.H. the Duchess of Fife and the Duke of Fife, K.T., Lord Lieutenant of the County of London.

Situated on the north-eastern corner of the Horton Estate (facing the Epsom Downs), purchased in 1896 for asylum purposes, and on which the Manor Asylum (for 700 female lunatics) and the Horton Asylum (for 2,000 lunatics) have already been erected, it has a demesne of 112 acres, to be devoted to colony purposes, separated from the rest of the estate by a public road. 